\title{
Demographics and medical disorders associated with smoking: a population- based study
}

\author{
Wei-Sheng Chung ${ }^{1,2,3}$, Pei-Tseng Kung ${ }^{4,5+}$, Hui-Yun Chang ${ }^{2}$ and Wen-Chen Tsai ${ }^{2^{*}+}$
}

\begin{abstract}
Background: Few studies have investigated factors associated with smoking behaviors. In this population-based study, we investigated demographics and medical comorbid diseases to establish a prediction model for smoking behaviors by using the National Health Interview Survey (NHIS) and National Health Insurance Research Database (NHIRD).

Methods: We enrolled individuals aged $\geq 40$ years who had participated in the NHIS in 2001, 2005, and 2009. We identified the smoking behaviors of the study participants in the NHIS. Smoking behaviors were divided into ever smokers (current smokers and ex-smokers) and nonsmokers (never smokers).We defined medical comorbid disorders of the study participants by using medical claim data from the NHIRD. We used multivariable logistic regression models to calculate the adjusted odds ratio and 95\% confidence interval for variables associated with smoking. The significant variables in the multivariable model were included in the receiver operating characteristic curves (ROC) to predict the sensitivity and specificity of the model.

Results: In total, 26,375 participants (12,779 men and 13,596 women) were included in the analysis. The prevalence of smoking was $39.29 \%$. The mean ages of the 16,012 nonsmokers were higher than those of the 10,363 smokers (57.86 \pm 12.92 years vs. $53.59 \pm 10.82$ years). Men outnumbered women among smokers (68.18\% vs. 31.82\%). Male sex, young age and middle age, being insured categories, residence in suburban areas, and chronic obstructive pulmonary disease (COPD) were independent factors associated with smoking. The area under the ROC curve of these significant factors to predict smoking behaviors was $71.63 \%$.
\end{abstract}

Conclusion: Sex, age, insured categories, residence in suburban areas, and COPD were associated with smoking in people.

Keywords: Smoking, Sex, Age, Chronic obstructive pulmonary disease, Receiver operating curve

\section{Introduction}

Worldwide, the overall morbidity and mortality in adult smokers are approximately three times higher than those in adult nonsmokers [1]. Smoking leads to diseases and disability in nearly all organs of the body [2]. The major causes of excess mortality among smokers include cancer, pulmonary diseases, and vascular diseases [1].

\footnotetext{
* Correspondence: wtsai@mail.cmu.edu.tw

${ }^{\dagger}$ Pei-Tseng Kung and Wen-Chen Tsai contributed equally to this work.

${ }^{2}$ Department of Health Services Administration, China Medical University, No. 91, Hsueh-Shih Road" Taichung 40402, Taiwan

Full list of author information is available at the end of the article
}

Hypertension, coronary artery disease (CAD), and stroke are well-established factors of morbidity relating to tobacco smoking [3-5]. Chronic obstructive pulmonary disease (COPD), a heterogeneous disorder causing progressively irreversible airflow limitation, is strongly related to smoking. Smoking accounts for 8 out of 10 COPD-related deaths [6]. The World Health Organization estimated that COPD will become the third leading cause of death by 2030 [7].

Approximately 4 million smokers were present in Taiwan and caused an estimated 18,000 smoke-related

C C The Author(s). 2020 Open Access This article is licensed under a Creative Commons Attribution 4.0 International License, which permits use, sharing, adaptation, distribution and reproduction in any medium or format, as long as you give appropriate credit to the original author(s) and the source, provide a link to the Creative Commons licence, and indicate if changes were made. The images or other third party material in this article are included in the article's Creative Commons licence, unless indicated otherwise in a credit line to the material. If material is not included in the article's Creative Commons licence and your intended use is not permitted by statutory regulation or exceeds the permitted use, you will need to obtain permission directly from the copyright holder. To view a copy of this licence, visit http://creativecommons.org/licenses/by/4.0/ The Creative Commons Public Domain Dedication waiver (http://creativecommons.org/publicdomain/zero/1.0/) applies to the data made available in this article, unless otherwise stated in a credit line to the data. 
death annually [8]. Continued tobacco use results from nicotine addiction, insufficient awareness of risk, and difficulty in abstinence plans, which are driven by diverse psychosocial and socioenvironmental factors, as well as physiological dependence [9]. In older adults, smoking behaviors are more common in men and in those with low education levels, poor health perception, and unmarried status [10].

Information on smoking behaviors is not available in the National Health Insurance Research Database (NHIRD) [11-14]. The evaluation of the effects of smoking on disease development by using the NHIRD is difficult and a couple of epidemiologic studies have listed smoking behaviors as a limitation [15-18]. Therefore, establishing a model to predict smoking behaviors is critical if the researchers do not have access to the study participants. We developed a model that used data on demographics and medical comorbidities from both the National Health Interview Survey (NHIS) and NHIRD to predict smoking behaviors.

\section{Methods}

\section{Data sources}

The Taiwan Ministry of Health and Welfare (formerly Department of Health) has implemented the National Health Interview Survey (NHIS) periodically since 1992 to understand the current status of mental and physical health, health risk behaviors, and medical care utilization. The study participants were national representative samples in the NHIS, which is widely recognized as the most comprehensive and reliable health survey of the civilian, noninstitutionalized, and household population in Taiwan. The Taiwanese government launched a universal National Health Insurance program in Taiwan in 1995, which currently covers more than $99.68 \%$ of the country's residents and is contracted with 97\% of healthcare institutions. The National Health Research Institute (NHRI) has created a research data set, NHIRD, containing the claims data of outpatient, inpatient, emergency, and dental care as well as data on prescription drugs dispensed. The NHRI scrambles the identification of the beneficiaries before releasing the NHIRD for public health research. The current study used the NHIS databases of 2001, 2005, and 2009 combined with the NHIRD from 2000 to 2012. Participants younger than 40 years and with incomplete demographics were excluded. We conducted a population-based cohort study and used the diagnoses of medical disorders coded in the International Classification of Disease, Ninth Revision, Clinical Modification (ICD-9-CM), 2001 edition. The Institutional Review Board of authors' affiliated organization approved this study (CMUH106REC3-080). The informed consent was waived because of encrypted identification number.

\section{Definition of outcome variables}

We identified the smoking behaviors of the study participants in the NHIS. Smoking behaviors were divided into ever smokers (current smokers and ex-smokers) and nonsmokers (never smokers). Current smokers were individuals who smoked on most or all days, and exsmokers were individuals who had smoked in the past. The outcome variable was cigarette smoking without any other combustible tobacco product.

\section{Definition of relevant variables}

Data were classified on the basis of sex (male and female) and age $(40-64,65-74$, and $>74$ years). The insurance categories were category I (employers, employees, and their families in private and public institutions, as well as military personnel), II (occupation union members), III (members of farmers, fishermen and irrigation associations), V (members of low-income households), and VI (veterans and dependents, and unemployed households and their dependents registered in township, city, and district offices). Insured monthly salary categorization of each beneficiary was as follows: $\leq 17$, 280 New Taiwan dollars (NTD), 17,280-22,800 NTD, 22,801-28,800 NTD, 28,801-36,300 NTD, 36,301-45, 800 NTD, 45,801-57,800 NTD, 57,801-72,800 NTD, and $>72,800$ NTD. The considered medical comorbid disorders, defined as the patients being hospitalized once or receiving three or more outpatient diagnoses (principal or secondary) within 365 days of receiving their diagnosis, were hypertension (ICD-9-CM 401-405), stroke (ICD-9-CM 430-438), CAD (ICD-9-CM 410-414), and COPD (ICD-9-CM 491, 492, and 496). The degree of urbanization of residence area where a patient lives was classified into levels, with Level 1 indicating the highest degree of urbanization and Level 7 the lowest.

\section{Statistical analysis}

The distribution of demographic characteristics and comorbidities of ever smokers and nonsmokers was compared. The Chi-square test and two sample Student's $t$ test were used to compare categorical variables and continuous variables, respectively. Furthermore, univariate and multivariable logistic regression models were used to calculate the odds ratio (OR) and 95\% confidence interval (CI) for variables associated with ever smokers. The significant variables in the multivariable model were included in the receiver operating curves (ROC) to predict the sensitivity and specificity of the model. The area under the ROC curve represents the efficiency of the prediction model in discriminating between ever smokers and nonsmokers [19]. Data were analyzed and managed using SAS 9.4 (SAS Institute, Inc., Cary, NC, USA). Two-tailed $P<0.05$ was considered statistically significant. 


\section{Results}

\section{Demographic characteristics and comorbidities of study} participants

A total of 26,375 participants $-12,779$ men and 13,596 women-were included in the analysis. The mean age of the study participants was $56.18 \pm 12.31$ years. Most participants (53.44\%) were aged 40-54 years. Among these study participants, 10,363 people (39.29\%) were ever smokers. The majority of the study participants (84.04\%) were insured under the category of employers, employees, and their families. Only $1 \%$ of the study participants were members of low-income households. Moreover, $47.94 \%$ of the study participants resided in suburban areas. The prevalent medical comorbid disorders in the study participants were hypertension (27\%), CAD (8.66\%), stroke (6.14\%), and COPD (5.04\%). The prevalence rate of ever smoking accounted for $39.29 \%$ of the study participants. Furthermore, $35.55 \%$ of the study participants had participated in adult preventive care. (Table 1).

\section{Demographic characteristics and comorbidities between ever smokers and nonsmokers}

Most ever smokers were men (68.18\%) and in the age group of $40-64$ years $(85.06 \%)$. By contrast, most nonsmokers were women (64.31\%), and $67.89 \%$ were $40-64$ years. The mean age of nonsmokers were higher than that of ever smokers $(57.86 \pm 12.92 \mathrm{y}$ vs. $53.59 \pm 10.82 \mathrm{y}$, $P<0.001)$. More ever smokers resided in the suburban areas compared with nonsmokers (47.94\% vs. $44.59 \%)$. The prevalence of the following medical comorbid disorders was higher in the nonsmokers than in the ever smokers: COPD (5.26\% vs. $4.70 \%)$, hypertension $(29.56 \%$ vs. $23.05 \%)$, stroke (6.88\% vs. $5.00 \%)$, and CAD $(9.67 \%$ vs. $7.09 \%)$. More nonsmokers tended to receive adult preventive care than ever smokers (36.51\% vs. $34.06 \%)$. (Table 2).

\section{Factors associated with ever smokers}

Table 3 lists factors associated with ever smokers by using multivariable logistic regression. Men exhibited a 4.18-fold adjusted OR of ever smoking compared with women (95\% CI = 3.96-4.42). Compared with individuals aged $>74$ years, those aged $40-54$ years and $55-64$ years exhibited a 3.12 -fold $(95 \% \mathrm{CI}=2.79-3.49)$ and 3.16-fold (95\% CI $=2.82-3.54$ ) adjusted OR of ever smoking. Compared with insured category I, other insured categories exhibited a significant association with ever smoking. Individuals residing in suburban areas exhibited a 1.09-fold adjusted OR of ever smoking compared with those residing in urban areas (95\% CI $=1.01-1.17$ ). COPD exhibited a 1.15-fold adjusted OR of ever smoking (95\% CI $=1.02-1.31)$. Furthermore, we incorporated the factors significantly associated with ever smoking
Table 1 Demographic characteristics and comorbidities of study participants

\begin{tabular}{|c|c|c|c|c|c|}
\hline Variables & $\mathrm{N}$ & (\%) & Variables & $\mathrm{N}$ & (\%) \\
\hline Sex & & & Insured category & & \\
\hline Men & 12,779 & $(48.45)$ & Categorized I & 9883 & $(37.47)$ \\
\hline Women & 13,596 & $(51.55)$ & Categorized II & 5718 & $(21.68)$ \\
\hline Age (y) & & & Categorized III & 6566 & $(24.89)$ \\
\hline $40-54$ & 14,096 & $(53.44)$ & Categorized V & 265 & $(1.00)$ \\
\hline $55-64$ & 5589 & (21.19) & Categorized VI & 3943 & (14.95) \\
\hline $65-74$ & 3928 & $(14.89)$ & \multicolumn{3}{|c|}{ Insured monthly salary (NTD) } \\
\hline$>74$ & 2765 & $(10.48)$ & $\leq 17,280$ & 1441 & (5.46) \\
\hline Comorbidity & & & $17,280-22,800$ & 13,616 & $(51.62)$ \\
\hline COPD & & & $22,801-36,300$ & 6150 & $(23.32)$ \\
\hline No & 25,045 & $(94.96)$ & $>36,301$ & 5168 & (19.59) \\
\hline Yes & 1330 & $(5.04)$ & \multicolumn{3}{|c|}{ Urbanization of residence areas } \\
\hline Hypertension & & & I & 5477 & $(20.77)$ \\
\hline No & 19,253 & $(73.00)$ & II, III & 12,107 & $(45.90)$ \\
\hline Yes & 7122 & $(27.00)$ & IV, V & 5761 & $(21.84)$ \\
\hline Stroke & & & $\mathrm{VI}, \mathrm{VII}$ & 3030 & (11.49) \\
\hline No & 24,756 & (93.86) & Smoking & & \\
\hline Yes & 1619 & $(6.14)$ & No & 16,012 & $(60.71)$ \\
\hline CAD & & & Yes & 10,363 & (39.29) \\
\hline No & 24,091 & $(91.34)$ & & & \\
\hline Yes & 2284 & $(8.66)$ & & & \\
\hline \multicolumn{6}{|c|}{ Adult preventive care } \\
\hline No & 16,999 & $(64.45)$ & & & \\
\hline Yes & 9376 & (35.55) & & & \\
\hline
\end{tabular}

into the prediction model; the area under the ROC curve was $71.63 \%$. (Fig. 1).

\section{Discussion}

Smoking leads to disease and disability of nearly every organ of the body $[2,20]$. Smoking also remains the leading preventable cause of premature death [21, 22]. The evaluation of the factors associated with smoking behaviors plays a vital role in controlling tobacco use. This is the first study to predict smoking behaviors by using a population-based cohort through a combination of the NHIS database and NHIRD. We observed that sex, age, insured category, residence in suburban areas, and COPD were independent risk factors associated with smoking. Combining these significant risk factors can yield a prediction accuracy rate of $71.63 \%$ for people with smoking behaviors.

This study retrieved the database of NHIS in the year 2001, 2005, and 2009, which indicated a smoking prevalence rate of $39.29 \%$. Previous studies have demonstrated approximate smoking prevalence rates of 33 and $22 \%$ in Taiwan in 2002 and 2007, respectively [8, 23]. The 
Table 2 Demographics and comorbidities between ever smokers and nonsmokers

\begin{tabular}{|c|c|c|c|c|c|c|}
\hline \multirow[t]{2}{*}{ Variables } & \multirow[t]{2}{*}{ Total } & \multicolumn{2}{|c|}{ Non-smokers } & \multicolumn{2}{|c|}{ Ever smokers } & \multirow[t]{2}{*}{$P$-value } \\
\hline & & $\mathrm{N}$ & $(\%)$ & $\mathrm{N}$ & (\%) & \\
\hline Total & 26,375 & 16,012 & $(60.71)$ & 10,363 & (39.29) & \\
\hline Sex & & & & & & $<0.001$ \\
\hline Men & 12,779 & 5714 & (35.69) & 7065 & $(68.18)$ & \\
\hline Women & 13,596 & 10,298 & $(64.31)$ & 3298 & $(31.82)$ & \\
\hline Age (y) & & & & & & $<0.001$ \\
\hline $40-54$ & 14,096 & 7785 & $(48.62)$ & 6311 & $(60.9)$ & \\
\hline $55-64$ & 5589 & 3085 & $(19.27)$ & 2504 & $(24.16)$ & \\
\hline $65-74$ & 3928 & 3010 & $(18.80)$ & 918 & $(8.86)$ & \\
\hline$>74$ & 2762 & 2132 & (13.32) & 630 & $(6.08)$ & \\
\hline Mean \pm SD & $56.18 \pm 12.31$ & $57.86 \pm$ & & $53.59 \pm$ & & $<0.001^{5}$ \\
\hline Insured category & & & & & & $<0.001$ \\
\hline Category I & 9883 & 5911 & (36.92) & 3972 & (38.33) & \\
\hline Category II & 5718 & 3212 & $(20.06)$ & 2506 & $(24.18)$ & \\
\hline Category III & 6566 & 4376 & $(27.33)$ & 2190 & $(21.13)$ & \\
\hline Category V & 265 & 118 & $(0.74)$ & 147 & $(1.42)$ & \\
\hline Category VI & 3943 & 2395 & (14.96) & 1548 & $(14.94)$ & \\
\hline Insured monthly salary (NTD) & & & & & & $<0.001$ \\
\hline$\leq 17,280$ & 1441 & 863 & $(5.39)$ & 578 & $(5.58)$ & \\
\hline $17,280-22,800$ & 13,616 & 8611 & (53.78) & 5005 & $(48.30)$ & \\
\hline $22,801-36,300$ & 6150 & 3581 & $(22.36)$ & 2569 & $(24.79)$ & \\
\hline$>36,301$ & 5168 & 2957 & $(18.47)$ & 2211 & $(21.34)$ & \\
\hline Urbanization of residence area & & & & & & $<0.001$ \\
\hline 1 & 5477 & 3363 & $(21.00)$ & 2114 & $(20.40)$ & \\
\hline$\|\|$, & 12,107 & 7139 & $(44.59)$ & 4968 & $(47.94)$ & \\
\hline IV, V & 5761 & 3594 & $(22.45)$ & 2167 & $(20.91)$ & \\
\hline $\mathrm{VI}, \mathrm{VII}$ & 3030 & 1916 & $(11.97)$ & 1114 & $(10.75)$ & \\
\hline \multicolumn{7}{|l|}{ Comorbidity } \\
\hline COPD & & & & & & 0.040 \\
\hline No & 25,045 & 15,169 & $(94.74)$ & 9876 & $(95.3)$ & \\
\hline Yes & 1330 & 843 & $(5.26)$ & 487 & $(4.70)$ & \\
\hline Hypertension & & & & & & $<0.001$ \\
\hline No & 19,253 & 11,279 & (70.44) & 7974 & $(76.95)$ & \\
\hline Yes & 7122 & 4733 & $(29.56)$ & 2389 & $(23.05)$ & \\
\hline Stroke & & & & & & $<0.001$ \\
\hline No & 24,756 & 14,911 & $(93.12)$ & 9845 & $(95.00)$ & \\
\hline Yes & 1619 & 1101 & $(6.88)$ & 518 & $(5.00)$ & \\
\hline CAD & & & & & & $<0.001$ \\
\hline No & 24,091 & 14,463 & $(90.33)$ & 9628 & $(92.91)$ & \\
\hline Yes & 2284 & 1549 & $(9.67)$ & 735 & $(7.09)$ & \\
\hline Adult preventive care & & & & & & $<0.001$ \\
\hline No & 16,999 & 10,166 & $(63.49)$ & 6833 & $(65.94)$ & \\
\hline Yes & 9376 & 5846 & (36.51) & 3530 & (34.06) & \\
\hline
\end{tabular}

Chi-square test; ${ }^{5}$ Two sample Student's $t$ test. 
Table 3 Logistic regression model evaluating factors associated with ever smoking

\begin{tabular}{|c|c|c|c|c|c|c|c|c|}
\hline \multirow[t]{2}{*}{ Variables } & \multicolumn{4}{|c|}{ Unadjusted } & \multicolumn{4}{|c|}{ Adjusted } \\
\hline & OR & \multicolumn{2}{|c|}{$(95 \% \mathrm{Cl})$} & $P$ value & OR & \multicolumn{2}{|c|}{$(95 \% \mathrm{Cl})$} & $P$ value \\
\hline \multicolumn{9}{|l|}{ Sex } \\
\hline Women & 1 & & & & 1 & & & \\
\hline Men & 3.86 & (3.66, & 4.07) & $<0.001$ & 4.18 & (3.96, & 4.42) & $<0.001$ \\
\hline \multicolumn{9}{|l|}{ Age (y) } \\
\hline$>74$ & 1 & & & & 1 & & & \\
\hline $40-54$ & 2.74 & $(2.50$ & 3.02) & $<0.001$ & 3.12 & $(2.79$, & 3.49) & $<0.001$ \\
\hline $55-64$ & 2.75 & $(2.48$ & 3.05) & $<0.001$ & 3.16 & $(2.82$, & 3.54) & $<0.001$ \\
\hline $65-74$ & 1.03 & $(0.92$ & $1.16)$ & 0.592 & 1.09 & (0.96, & $1.23)$ & 0.176 \\
\hline \multicolumn{9}{|l|}{ Insured Category } \\
\hline Category I & 1 & & & & 1 & & & \\
\hline Category II & 1.16 & (1.09, & 1.24) & $<0.001$ & 1.31 & $(1.20$, & 1.43) & $<0.001$ \\
\hline Category III & 0.75 & $(0.70$ & $0.80)$ & $<0.001$ & 1.18 & (1.05, & $1.31)$ & 0.004 \\
\hline Category V & 1.85 & $(1.45$ & 2.37) & $<0.001$ & 2.09 & $(1.56$ & 2.80) & $<0.001$ \\
\hline Category VI & 0.96 & (0.89, & 1.04) & 0.313 & 1.25 & $(1.13$ & 1.38) & $<0.001$ \\
\hline \multicolumn{9}{|c|}{ Insured monthly salary (NTD) } \\
\hline$\leq 17,280$ & 1 & & & & 1 & & & \\
\hline $17,280-22,800$ & 0.87 & $(0.78$ & $0.97)$ & 0.012 & 0.90 & $(0.78$ & 1.04) & 0.160 \\
\hline $22,801-36,300$ & 1.07 & (0.95, & 1.20) & 0.249 & 1.11 & (0.96, & 1.28) & 0.149 \\
\hline$>36,301$ & 1.12 & (0.99, & 1.26) & 0.070 & 0.98 & $(0.85$ & 1.13) & 0.800 \\
\hline \multicolumn{9}{|c|}{ Urbanization of residence area } \\
\hline । & 1 & & & & 1 & & & \\
\hline$\|\|$, & 1.11 & $(1.04$ & 1.18) & 0.002 & 1.09 & (1.01, & 1.17) & 0.019 \\
\hline $\mathrm{N}, \mathrm{V}$ & 0.96 & $(0.89$ & 1.04) & 0.284 & 1.05 & $(0.95$ & 1.15) & 0.344 \\
\hline $\mathrm{VI}, \mathrm{VII}$ & 0.93 & $(0.84$ & 1.01) & 0.095 & 1.03 & $(0.92$ & 1.15) & 0.609 \\
\hline
\end{tabular}

\section{Comorbidity}

COPD

\section{No}

Yes

Hypertension

No
Yes

\section{Stroke}

No

Yes

CAD

No

Yes

Adult preventive care

$$
\text { No }
$$$$
\text { Yes }
$$

\section{1}

0.89

\section{1}

0.71

1

0.71

1

0.71

(0.79,

0.99)

0.041

.15

(1.02,

1.31)

0.029

0.71

(0.67,

0.76 )

$<0.001$

0.95

(0.89,

1.02)

0.140

(0.64,

0.79)

$<0.001$

1.02

(0.90,

1.16)

0.730

(0.65,

0.78)

$<0.001$

0.99

$(0.88$,

1.13)

0.922

0.90

(0.85,

0.95)

$<0.001$

1.05

(0.99,

1.11)

0.116

discrepancy between our finding and those of previous reports may be attributed to the differences in the methodologies. The participants in the current study were aged $\geq 40$ years. Most ever smokers in the current study were men, which is consistent with the finding of previous reports [24-26]. A Global Adult Tobacco Survey in 


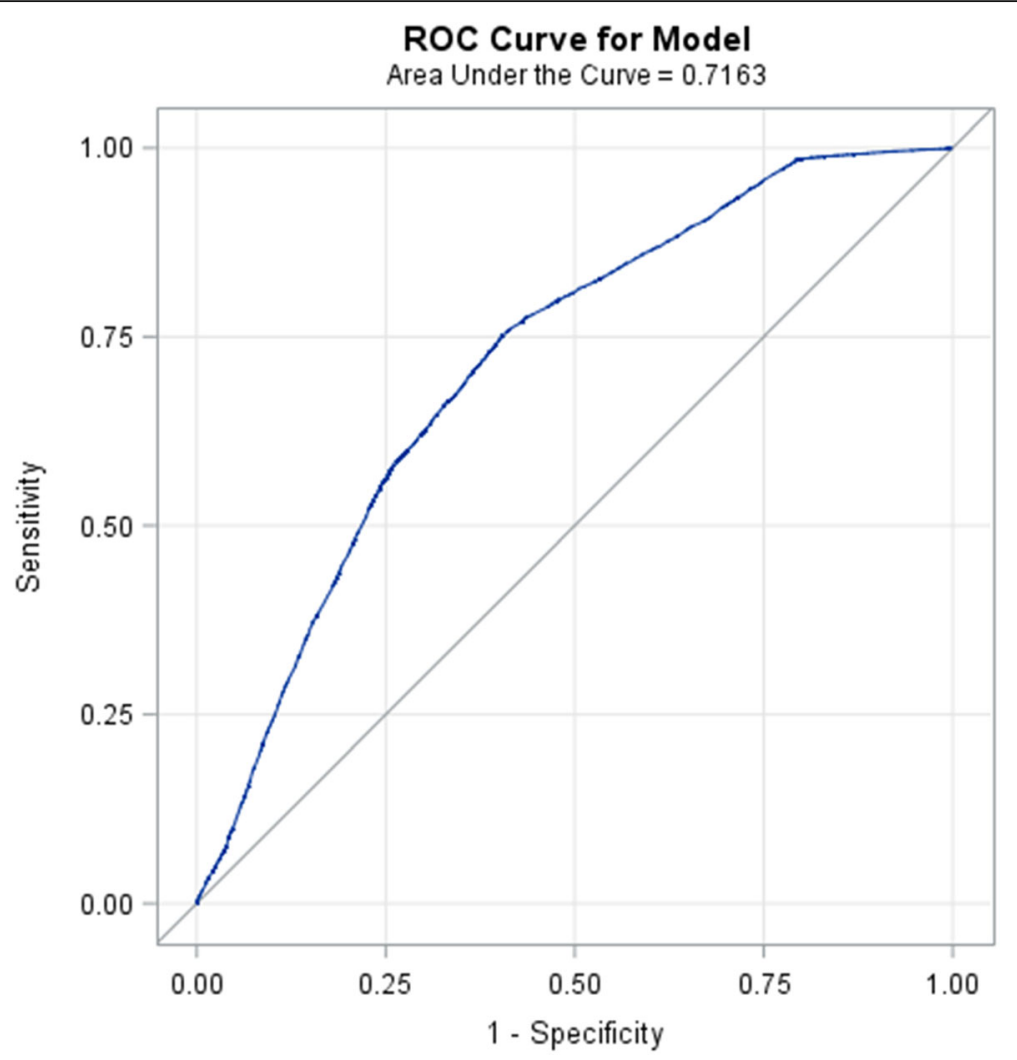

Fig. 1 ROC curve of the prediction model for ever smokers

16 countries revealed that $48.6 \%$ of men and $11.3 \%$ of women consumed tobacco [26]. In the current study, $55.3 \%$ of men and $24.3 \%$ of women were ever smokers.

The higher prevalence of comorbidities in nonsmokers than in ever smokers may be attributed the higher mean age of nonsmokers than that of ever smokers. The prevalence of comorbidities such as hypertension, stroke, CAD, and COPD increased with age [27-29]. The increase in blood pressure with age is related to structural changes in the arteries and arterial wall stiffness, which results in the increasing risks of CAD and stroke with age $[29,30]$.

COPD is characterized by productive cough and dyspnea, a progressive decline in lung function, a deteriorating effect on quality of life, and a high risk of morbidity and early mortality [31]. Environmental toxin exposure, genetic abnormalities, and accelerated aging are risk factors of COPD [32]. However, smoking is identified as the most common risk factor associated with COPD development $[31,32]$. In the present study, COPD was significantly associated with smoking after adjustment for covariates.

Certain limitations should be considered while interpreting the study findings. First, the current study provided a correlation rather than a causal connection. Second, the study did not define the dose-response relationship between smoking and associated covariates. Third, despite a meticulous study design with adequate control of covariates, a key limitation of this study is the potential for bias because of possible unmeasured covariates. Fourth, we did not have information to discern the order in which smoking behaviors occurred or when COPD developed among participants. Finally, this study did not include the sample weight in the analyses which may mitigate the representative of nationwide population. However, the strength of our study is that we used a large population-based cohort from the NHIS through random sampling of the nationwide representatives and combined with the medical reimbursement data of the study participants from the NHIRD.

\section{Conclusions}

The present study indicates that sex, age, insured categories, residence in suburban areas, and COPD are significantly associated with smoking behaviors. The prediction model yields a relatively high accuracy in discriminating between ever smokers and never smokers.

\section{Abbreviations}

CAD: Coronary artery disease; COPD: Chronic obstructive pulmonary disease; NHIS: National Health Interview Survey; NHI: National health Insurance; NHIRD: National Health Insurance Research Database; NHRI: National Health Research Institute; NC: North Carolina; Cl: Confidence interval; ROC: Receiver 
operating curves; ICD-9-CM: International Classification of Diseases, Ninth Revision, Clinical Modification; OR: Odds ratio; NTD: New Taiwan Dollar

\section{Acknowledgments}

We are grateful for use of the National Health Insurance Research Database and National Health Interview Survey provided by the Science Center, the Ministry of Health and Welfare, Taiwan. We are also grateful to Health Data Science Center, China Medical University Hospital for providing administrative, technical and funding support.

\section{Authors' contributions}

WSC and WCT designed the study. PTK and WCT obtained data. WSC, PTK, and WCT were responsible for study conceptualization and developing the analytical plan. HYC and PTK analyzed data. WSC, PTK, HYC, and WCT drafted the manuscript. WSC, PTK and WCT revised manuscript. PTK and WCT obtained funding source. The author(s) read and approved the final manuscript.

\section{Funding}

This study was supported by the grant (DMR-108-112) from China Medical University. The funders had no role in study design, data collection and analysis, decision to publish, or preparation of the manuscript.

\section{Availability of data and materials}

Regarding the data availability, data were obtained from the National Health Interview and Survey and the National Health Insurance Research Database published by the Ministry of Health and Welfare, Taiwan. Due to legal restrictions imposed by the Taiwan government related to the Personal Information Protection Act, the database cannot be made publicly available. All researchers can apply for using the databases to conduct their studies. Requests for data can be sent as a formal proposal to the Health and Welfare Data Science Center of the Ministry of Health and Welfare (http:// www.mohw.gov.tw/EN/Ministry/Index.aspx). Any raw data are not allowed to be brought out from the Health and Welfare Data Science Center. The restrictions prohibited the authors from making the minimal data set publicly available.

\section{Ethics approval and consent to participate}

This study used anonymized secondary data retrievedd from the National Health Interview and Survey and the National Health Insurance Research Database. The informed consent was waived by the ethics committee because of encrypted identification number. This study has been approved by the research ethics committee at China Medical University (IRB: CMUH106-REC3-080) Taiwan.

\section{Consent for publication}

Not applicable.

\section{Competing interests}

The authors declare that they have no competing interests.

\section{Author details}

'Department of Internal Medicine, Taichung Hospital, Ministry of Health and Welfare, Taichung, Taiwan. ${ }^{2}$ Department of Health Services Administration, China Medical University, No. 91, Hsueh-Shih Road,"Taichung 40402, Taiwan. ${ }^{3}$ Department of Healthcare Administration, Central Taiwan University of Science and Technology, Taichung, Taiwan. ${ }^{4}$ Department of Healthcare Administration, Asia University, Taichung, Taiwan. ${ }^{5}$ Department of Medical Research, China Medical University Hospital, China Medical University, Taichung, Taiwan.

\section{Received: 23 May 2019 Accepted: 6 May 2020}

Published online: 15 May 2020

\section{References}

1. CDC. Tobacco-Related Mortality. 2016 https://www.cdc.gov/tobacco/data_ statistics/fact_sheets/health_effects/tobacco_related_mortality/. Accessed 14 Oct 2017.

2. Jamal A, Homa DM, O'Connor E, Babb SD, Caraballo RS, Singh T, et al. Current cigarette smoking among adults - United States, 2005-2014. MMWR Morb Mortal Wkly Rep. 2015;64(44):1233-40.
3. Yun M, Li S, Sun D, Ge S, Lai CC, Fernandez C, et al. Tobacco smoking strengthens the association of elevated blood pressure with arterial stiffness: the Bogalusa heart study. J Hypertens. 2015;33(2):266-74.

4. Shah RS, Cole JW. Smoking and stroke: the more you smoke the more you stroke. Expert Rev Cardiovasc Ther. 2010;8(7):917-32.

5. Ambrose JA, Barua RS. The pathophysiology of cigarette smoking and cardiovascular disease: an update. J Am Coll Cardiol. 2004;43(10):1731-7.

6. U.S. Department of Health and Human Services. The Health Consequences of Smoking - 50 Years of Progress: A Report of the Surgeon General. Atlanta, GA: U.S. Department of Health and Human Services, Centers for Disease Control and Prevention, National Center for Chronic Disease Prevention and Health Promotion, Office on Smoking and Health, 2014.

7. WHO. Chronic obstructive pulmonary disease (COPD). 2016 http://www who.int/respiratory/copd/en/. Accessed 14 Oct 2017.

8. Mendel JR, Berg CJ, Windle RC, Windle M. Predicting young adulthood smoking among adolescent smokers and nonsmokers. Am J Health Behav. 2012;36(4):542-54.

9. Giovino GA. Epidemiology of tobacco use among US adolescents. Nicotine Tob Res. 1999;1(Suppl 1):S31-40.

10. Backinger $\mathrm{CL}$, Fagan P, Matthews E, Grana R. Adolescent and young adult tobacco prevention and cessation: current status and future directions. Tob Control. 2003;4(12 Suppl):Iv46-53.

11. Hammond D. Smoking behaviour among young adults: beyond youth prevention. Tob Control. 2005;14(3):181-5.

12. WHO. Tobacco Use and Its Impact on Health.2016. http://www.who.int/ tobacco/publications/gender/en_tfi_gender_women_prevalence_tobacco_ use.pdf. Accessed 10 Oct 2017.

13. Peixoto SV, Firmo JO, Lima-Costa MF. Factors associated to smoking habit among older adults (the Bambui health and aging study). Rev Saude Publica. 2005;39(5):746-53.

14. Chung WS, Lin CL, Chen YF, Ho FM, Hsu WH, Kao CH. Increased stroke risk among adult asthmatic patients. Eur J Clin Investig. 2014;44(11):1025-33.

15. Hsu MT, Lin CL, Chung WS. Increased risk of acute coronary syndrome in patients with chronic pancreatitis: a Nationwide cohort analysis. Medicine. 2016;95(20):e3451.

16. Chung WS, Shen TC, Lin CL, Chu YH, Hsu WH, Kao CH. Adult asthmatics increase the risk of acute coronary syndrome: a nationwide populationbased cohort study. Eur J Intern Med. 2014;25(10):941-5.

17. Chung WS, Lin $\mathrm{CL}, \mathrm{Hsu} W H$, Kao $\mathrm{CH}$. lacreased risk of lung cancer among $p$

18. Hajian-Tilaki K. Receiver operating characteristic (ROC) curve analysis for medical diagnostic test evaluation. Caspian J Intern Med. 2013;4(2): 627-35.

19. The Health Consequences of Smoking - 50 Years of Progress: A Report of the Surgeon General. Atlanta: U.S. Department of Health and Human Services, Centers for Disease Control and Prevention, National Center for Chronic Disease Prevention and Health Promotion, Office on Smoking and Health, 2014: U.S. Department of Health and Human Services.; 2014. Available from: https://www.cdc.gov/tobacco/data_statistics/fact_sheets/ fast_facts/.Accessed 21 March 2017.

20. WHO. WHO Report on the Global tobacco epidemic, 2009. 2009.

21. Leung CM, Leung AK, Hon KL, Kong AY. Fighting tobacco smoking--a difficult but not impossible battle. Int J Environ Res Public Health. 2009;6(1): 69-83.

22. Lee JM, Liao DS, Ye CY, Liao WZ. Effect of cigarette tax increase on cigarette consumption in Taiwan. Tob Control. 2005;14(Suppl 1):i71-5.

23. Chang FC, Hu TW, Lo SY, Yu PT, Chao KY, Hsiao ML. Quit smoking advice from health professionals in Taiwan: the role of funding policy and smoker socioeconomic status. Tob Control. 2010;19(1):44-9.

24. Tsai YW, Tsai TI, Yang CL, Kuo KN. Gender differences in smoking behaviors in an Asian population. J Women's Health (2002). 2008;17(6):971-978.

25. Hitchman SC, Fong GT. Gender empowerment and female-to-male smoking prevalence ratios. Bull World Health Organ. 2011;89(3):195-202.

26. Giovino GA, Mirza SA, Samet JM, Gupta PC, Jarvis MJ, Bhala N, et al. Tobacco use in 3 billion individuals from 16 countries: an analysis of nationally representative cross-sectional household surveys. Lancet (London, Engl). 2012;380(9842):668-79

27. Chaudhry SI, Krumholz HM, Foody JM. Systolic hypertension in older persons. JAMA. 2004;292(9):1074-80.

28. Hollander M, Koudstaal PJ, Bots ML, Grobbee DE, Hofman A, Breteler MM. Incidence, risk, and case fatality of first ever stroke in the elderly population. The Rotterdam study. J Neurol Neurosurg Psychiatry. 2003;74(3):317-21. 
29. Jousilahti P, Vartiainen E, Tuomilehto J, Puska P. Sex, age, cardiovascular risk factors, and coronary heart disease: a prospective follow-up study of 14786 middle-aged men and women in Finland. Circulation. 1999;99(9):1165-72.

30. Pinto E. Blood pressure and ageing. Postgrad Med J. 2007:83(976):109-14.

31. Ramsey SD, Hobbs FD. Chronic obstructive pulmonary disease, risk factors, and outcome trials: comparisons with cardiovascular disease. Proc Am Thorac Soc. 2006;3(7):635-40.

32. GOLD. Global strategy for the diagnosis, management, and prevention of chronic obstructive pulmonary disease 2017 report. 2017. http://goldcopd. org/gold-2017-global-strategy-diagnosis-management-prevention-copd/. Accessed 30 March 2017.

\section{Publisher's Note}

Springer Nature remains neutral with regard to jurisdictional claims in published maps and institutional affiliations.

Ready to submit your research? Choose BMC and benefit from:

- fast, convenient online submission

- thorough peer review by experienced researchers in your field

- rapid publication on acceptance

- support for research data, including large and complex data types

- gold Open Access which fosters wider collaboration and increased citations

- maximum visibility for your research: over $100 \mathrm{M}$ website views per year

At BMC, research is always in progress.

Learn more biomedcentral.com/submissions 